\title{
MACHINING PROPERTIES OF Melia dubia WOOD
}

\author{
Sachin Gupta ${ }^{1}$, C.P. Singh ${ }^{1}$, V.S. Kishan-Kumar ${ }^{1, \diamond}$, Shikhar Shukla ${ }^{1}$
}

\begin{abstract}
In this paper result of working quality of Melia dubia is reported after testing them under six major wood working operations namely - planing, sanding, turning, shaping, boring and mortising based on Indian Standard. The wood performed extremely well under planing. In shaping, the performance was good enough. Though all the other operations yielded poor results, the composite rating factor which is an overall performance indicator was $35 \%$ more than that of Tectona grandis. The ease of working is only $93 \%$ compared to teak. The working quality index which was based on the composite rating factor and ease of working worked out to 107 taking Tectona grandis as 100 mainly because of the high performance under planing and shaping and good performance under sanding.
\end{abstract}

Keywords: Ease factor, planing, sanding, shaping, turning, working quality.

\section{INTRODUCTION}

Like the physical and mechanical properties, the working quality (or machining quality) of a timber also plays an important role in its utilization. Knowledge of working quality of timber is therefore necessary for its efficient utilization. Necessity of data on working quality of more and more native timbers is being felt. It is influenced by density, fibre structure, presence of interlocked grains, tension wood etc. Proper knowledge of working quality of lesser used timber species is becoming important day by day as traditional timbers are becoming scarce and beyond the reach of common man.

Many Indian species have been studied at Forest Research Institute, Dehradun for their working quality indices (WQI) and it has been reported that the working qualities ranged from poorer than to comparable to and better than that of Teak. For instance, the working properties of Jaonessia principes and Populus ciliata were reported to be poorer than that of teak (Pant et al. 1992).

Many species like Albizzia, Dalbergia sissoo and eucalypts had WQI (90-96) approaching or comparable to that of teak (Shukla et al. 1991). Performances of Acacia tortilis, Leucaena leucocephala and Picea smithiana were also comparable to teak (Pant et al. 2002). Jaitly et al. (1983) reported more than $90 \%$ WQI for Eucalyptus camaldulensis and Eucalyptus hybrid. E. camaldulensis responded better to planing with $20^{\circ}$ cutting angle. This species also gave clear and acceptable bores and mortises.

Araucaria cunninghamii, Azadirachta indica, Jakaranda acutifolia (jacaranda), were studied by Pant et al. (1992). Overall performance was better for A. cunninghamia, A. indica and J. acutifolia compared to teak. Pant et al. (2002) reported that Paulownia species and Ulmuswallichiana performed better than teak after subjecting them to the six wood working operations.

Working qualities of six Indian timbers obtained from a Northern State of India were reported by Pant et

${ }^{1}$ Forest Products Division, Forest Research Institute, New Forest, Uttarakhand, India.

•Corresponding author: kishankumarv@yahoo.com

Received: 10.10.2017 Accepted: 28.08.2018 
al. (1989). The species tested were maple (Acer oblongum), cypress (Cupressus torulosa), shisham (Dalbergia sissoo), vern-gair-Garhwal (Daphniphyllum himalayense), Indian olive (Olea glandulifera) and Indian oak (Quercus serrata). The results indicated that all the six species could be worked to an acceptable smooth surface though responses to operations were different for the six species.

Shukla et al. (1991) gave a review on the working qualities of 74 Indian timbers. They reported that some of the harder species could be planed to smooth surfaces with planer cutters having $25^{\circ}$ cutting angles. However, a few other species required a cutting angle of $30^{\circ}$. Whereas less harder woods of Mango and Pinus roxburghii required only a lesser cutting angle of $15^{\circ}$. Some timbers like that of Cinnamomum camphora and Araucaria araucana responded well to multiple cutting angles.

Against this background, a study was conducted to understand the machining qualities of Melia dubia (Synonym: Melia composita). This wood species is yet to be studied thoroughly from the utilization point of view. The wood of M. dubia belongs to the diffuse porous category (Saravanan et al. 2013a). Saravanan et al. (2013b) found this species suitable for paper pulp production and recommended a five year rotation for use in this sector. Another study showed that apart from paper industry, this species has mechanical properties suitable for plywood industry and energy values required for biomass based power generation (Saravanan et al. 2014). Studies on the gluing and bonding properties on the veneers of this species showed that panels made using urea formaldehyde and phenol formaldehyde adhesives meet the requirements of interior Grade (general purpose) and exterior grade (general purpose) plywoods (Uday et al. 2012). The finishing qualities of this species also have been recently reported with respect to the lusture and moisture inhibiting capacities provided by various commercial wood finishes (Gupta et al. 2016a, Gupta et al. 2016b).

\section{MATERIALS AND METHODS}

Fifteen kiln-dried (10-12\% moisture content) planks of size 1200x100x25 mm ${ }^{3}$ were prepared from plainsawn $25 \mathrm{~mm}$ thick material of a M. dubia tree of 15 years of age felled from the Forest Research Institute's campus to prepare samples for various tests. This mature tree had hardly any sapwood. The planks were sawn out from the main stem of the tree. The mean density of the wood thus obtained was $0,39 \mathrm{~kg} / \mathrm{m}^{3}$ (Kumar et al. 2018). From these planks, samples of sizes mentioned in Table 1 were prepared for various tests and wood working tests were carried out as per methods given in IS-8292 (BIS IS-8292 1992).

Table 1: Specimen sizes for each wood working operation.

\begin{tabular}{|c|c|c|c|}
\hline $\begin{array}{l}\text { Sl. } \\
\text { No. }\end{array}$ & Working operation & $\begin{array}{c}\text { No. of } \\
\text { samples }\end{array}$ & Size of each specimen (mm $x \mathrm{~mm} \times \mathrm{mm}$ ) \\
\hline 1 & Planing & \multirow[b]{2}{*}{15} & \multirow{2}{*}{$\begin{array}{l}900 \times 100 \times 25 \\
\text { (Both these operations were camied out on } \\
\text { each of the fifteen samples in the order of } \\
\text { sanding after planing) }\end{array}$} \\
\hline 2 & Sanding & & \\
\hline 3 & Shaping & \multirow[b]{3}{*}{15} & \multirow{3}{*}{$\begin{array}{l}300 \times 75 \times 25 \\
\text { (These three operations were camied out on } \\
\text { each of the fifteen samples in the order of } \\
\text { shaping followed by boring followed by } \\
\text { Mortising) }\end{array}$} \\
\hline 4 & Boring & & \\
\hline 5 & Mortising & & \\
\hline 6 & Tuming & 15 & $150 \times 25 \times 25$ \\
\hline
\end{tabular}

A schematic diagram of the samples cut for various tests is given in Figure 1. 


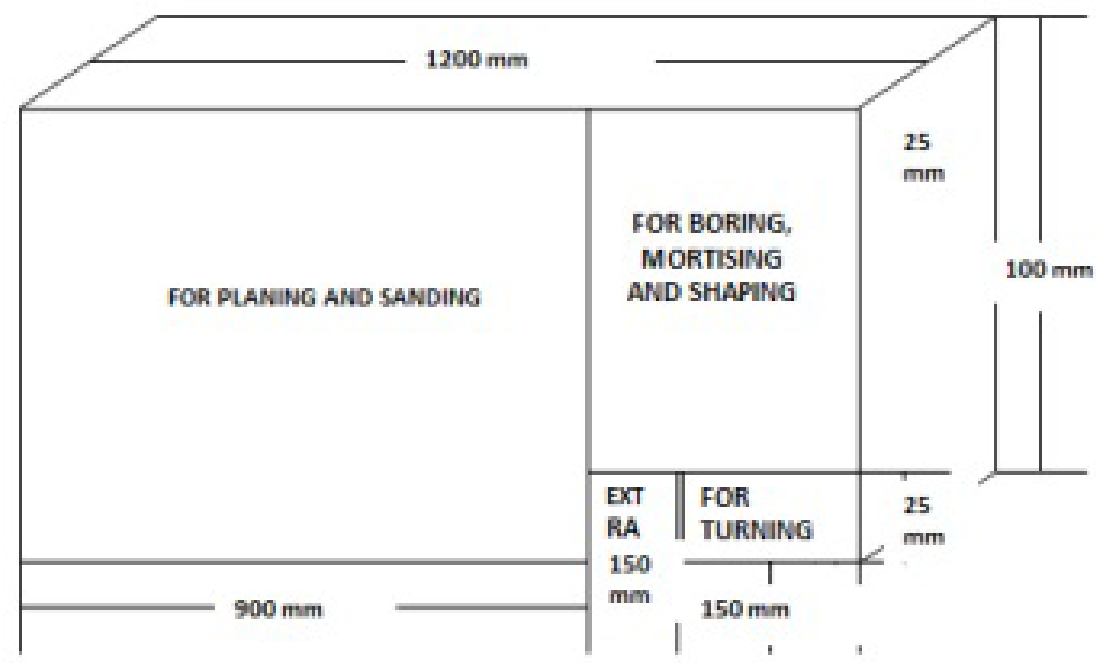

Figure 1: Plan for preparing samples from one plank.

The following were the machines used and their procedure for performing the six wood working operations:

Planing: A DC planer cum thicknesser machine (make Dominion) fitted with two knives diametrically opposite on a circular cutter block was used. Four sets of blades with cutting angles of $15^{\circ}, 20^{\circ}, 25^{\circ}$ and $30^{\circ}$ were used in that order. The grinding angle for the $25^{\circ}$ blade was $30^{\circ}$ and clearance angle was $15^{\circ}$. Speed of cutter block of diameter $100 \mathrm{~mm}$ was kept at $5000 \mathrm{rpm}$ and feed rate was $8,4 \mathrm{~m} / \mathrm{min}$. The cutting speed was $26,1 \mathrm{~m} / \mathrm{s}$.

Every specimen was passed two times through this machine, once along the grain and then the other face opposite to it. Immediately after each pass, the specimen was visually examined for planing defects. This was carried out with all the four sets of blades. A depth of cut of $1 \mathrm{~mm}$ was maintained for each pass so that in effect there was a total depth of cut of $2 \mathrm{~mm}$ after two passes. Power requirement in each planing operation was also recorded with the help of a wattmeter. Average value of power required per $\mathrm{cm}$ width of cut of the specimen was worked out and values were noted.

Sanding: Three drum endless belt sander (make Smith) with drum motors of $15 \mathrm{hp}$ each at $1725 \mathrm{rpm}$ was used in which drums carried sand papers of grit sizes 60,80 and 100 progressively. The same specimens used in planing were used for studying the sanding behavior. Each specimen was passed through the three drum sander at a feed rate of $3,6 \mathrm{~mm} / \mathrm{min}$ with a depth of $1 \mathrm{~mm}$ on each side. The cutting speed was $22,9 \mathrm{~m} / \mathrm{sec}$.

Shaping: A two-cutter spindle moulding machine (make Sonex Pelican $2840 \mathrm{rpm}$ ) mounted with cutters of quarter round profile capable of giving $2 \mathrm{~mm}$ deep sweep was used in this test. Fifteen specimen of size $300 \mathrm{x}$ $75 \times 25 \mathrm{~mm}^{3}$ were cut from the original plank. The edges of the specimen were shaped with the help of shaping cutter mounted on the moulding machine.

Boring: A single spindle electric boring machine (make Rockwell - hand feed type) having $3400 \mathrm{rpm}$ and a drill bit of carbon steel with single twist profile pointed type having $25 \mathrm{~mm}$ diameter was used in this test. The fifteen shaped specimen were used for this test. Each specimen was held in a suitable position and two holes were made through them near to one end. For the visual examination of the specimen, the four bored holes were cut in two directions, one along the grain and another across the grain.

Mortising: The same fifteen shaped and bored samples were used in this test. The test was done on a hollow chisel type single spindle electric mortising machine (make Oliver) running at $3000 \mathrm{rpm}$. The square chisel was of $12,5 \mathrm{~mm}$ in size. Each specimen was held in a suitable position and two mortises were made on them extending through into a hardwood backing. These mortises were made near the other end of the samples on which holes were bored previously. For the visual examination of the specimen, the mortises were cut along 
the grain and another across the grain.

Turning: 15 specimens of size $150 \times 25 \times 25 \mathrm{~mm}^{3}$ were used for this test. An auto-tool turnery lathe machine (make Crompton) of $3000 \mathrm{rpm}$ which turns samples into uniform shape and size was used for this test.

Immediately after each test, the specimens were visually examined for defects like raised grain, torn grain, fuzzy grain, chip mark and charring effect and were noted depending on the intensity of each defect. Defect values depending on the severity (visual assessment of how a defect can be rectified by subsequent operations like sanding, finishing etc.) from 1 to 5 were assigned as given in Table 2.

\section{Defect grading}

Table 2: Assignment of defect values.

\begin{tabular}{|l|c|}
\hline Defect severity & Assigned Value \\
\hline No defect (defect-free) & 0 \\
\hline Excellent & 1 \\
\hline Very Good & 2 \\
\hline Good & 3 \\
\hline Fair & 4 \\
\hline Poor & 5 \\
\hline
\end{tabular}

The calculations of various factors involved in arriving at the working quality index were carried out according to BIS IS-8292 1992 as explained by Shukla et al. (1991).

The defect values were compiled for each operation. The total defect values were then calculated for each sample (or surface) as the case may be. These were then grouped into five Grades of 1 to 5 according to the scheme shown in Table 3.

Table 3: Grading of samples/surfaces.

\begin{tabular}{|c|c|}
\hline Grade & Definition of grading \\
\hline 1 & Defect Value 0 (defect-free) \\
\hline 2 & Total Defect Value 1 \\
\hline 3 & Total Defect Value 2 \\
\hline 4 & Total Defect Value 3 \& 4 \\
\hline 5 & Total Defect Value 5 \& Above \\
\hline
\end{tabular}

After this, the numbers of samples/surfaces falling into each grade were counted from the compiled data for each operation and their percentages were calculated as follows:

- Let, Total number of samples/surfaces in an operation $=\mathrm{N}$

- $\quad$ Let the number of samples/surfaces falling in grade $1=\mathrm{n}$

- $\quad$ Then, $\%$ of samples/surfaces falling in grade $1=(\mathrm{n} \times 100) / \mathrm{N}$

\section{Rating factor}

After calculating the percentage of number of samples/surfaces falling in each grade, the next step was to arrive at the rating factors $\left(\mathrm{R}_{\mathrm{i}}\right)$ for each operation which are calculated as given in Table 4 . 
Table 4: Method of calculating the rating factors.

\begin{tabular}{|l|c|}
\hline Operation & Definition of Rating factor \\
\hline Planing & Percentage of grade 1 specimens \\
\hline Sanding & Percentage of grade 1 specimens \\
\hline Shaping & Total Percentage of grade $1 \& 2$ specimens \\
\hline Boring & Total Percentage of grade $1 \& 2$ specimens \\
\hline Mortising & Total Percentage of grade $1,2 \& 3$ specimens \\
\hline Tuming & Total Percentage of grade $1,2 \& 3$ specimens \\
\hline
\end{tabular}

Once rating factors have been estimated, the Adjustment factor $\left(\mathrm{A}_{\mathrm{i}}\right)$ needs to be calculated which is based on the magnitude of the best planing values for teak species. These values can either be generated in the laboratory or taken from literature. In the present study, the values for teak were taken from the literature (Pant et al. 2002). For this, the percentage value of a particular operation for teak is divided by the percentage value of teak for its planing operation. For instance, the adjustment factor for planing of teak would be 1.

Various operations are given due weightages $\left(\mathrm{W}_{\mathrm{i}}\right)$ as per the importance of the operation in working with wood (BIS IS-8292 1992). The weightage for sanding is the highest (5) because this operation is required in almost every type of wood products. This is followed by planing (4), Shaping (2), Boring (1), Mortising (1) and Turning (2). It is to mention that the ASTM standard though did not specify weightages to individual operations, it was stressed that the depth of a defect is more important than its area covered (ASTM D-1666 1987).

In the next step, the weighted averages for teak and the species under investigation would be calculated as Equation 1:

$$
\text { Weighted average }=\frac{\sum R i A i W i}{\sum W i}
$$

Where $\mathrm{Ri}$ is the rating factor for each operation, $\mathrm{Ai}$ is the adjustment factor and Wi is the weightage for each operation.

BIS IS-8292 1992 defines a figure indicative of the overall performance of a species under all wood working tests relative to teak which serves as an index which is termed as the Composite Rating Factor (CRF). This is calculated as Equation 2:

$$
C R F=\frac{\text { Weighted average of species under investigation }}{\text { Weighted average of teak }} \times 100
$$

The next step is to calculate the Ease factor (EF) which is an indication of ease of working of the species under study relative to teak in wood working tests (BIS IS-8292 1992). It is evaluated by measuring power requirements per $\mathrm{cm}$ width of the species studied to achieve a cutting depth of $1,6 \mathrm{~mm}$ under planing operation. The power requirement is calculated as Equation 3:

Power requirement $=$ Power requirement in cutting condition $(\mathrm{kW} / \mathrm{cm})-$ Power requirement in the idle running condition (3)

These are noted during the planing operation by reading the power on a wattmeter in idle running condition and when planing samples is in progress Equation 4.

$$
E F=\frac{\text { Power requirement of teak }}{\text { Power requirement of species }} \times 100
$$


Here also the value for teak can be tested in the laboratory or taken from literature. In the present case, value given by Pant et al. (2002) was adopted for the purpose.

\section{Estimation of working quality index (WQI)}

According to BIS IS-8292 1992, besides the physical and mechanical properties of a timber, its working quality under different wood working operations also form an important consideration for determining its suitability for the manufacture of timber products. Towards this, the BIS IS-8292 1992 formulated the working quality index (WQI) which is calculated by combining the composite rating factor and ease factor which are discussed above. According to the standard, in the calculation of WQI, the CRF or overall performance is given a weightage of "one" whereas the ease factor or the reflection of power requirements is given a weightage of "two". WQI is calculated as Equation 5:

$$
W Q I=\frac{C R F+2 E F}{3}
$$

\section{RESULTS AND DISCUSSION}

Since planing was done on the fifteen samples using four different cutting angles, the rating factors for this operation are given separately. These are given in Table 5.

Table 5: Percentage of M. dubia planed surfaces lying in different grades.

\begin{tabular}{|c|c|c|c|c|c|c|}
\hline Cutting Angle & Grade 1 & Grade 2 & Grade 3 & Grade 4 & Grade 5 & Total \% \\
\hline $15^{\circ}$ & 50 & 40 & 10 & 0 & 0 & 100 \\
\hline $20^{\circ}$ & 47 & 23 & 30 & 0 & 0 & 100 \\
\hline $25^{\circ}$ & 60 & 3 & 30 & 7 & 0 & 100 \\
\hline $30^{\circ}$ & 57 & 13 & 20 & 10 & 0 & 100 \\
\hline
\end{tabular}

A close observation of different defects that occurred in the species indicated that raised and torn grains were most common followed by chipped grain. In some specimens, roughness was also observed. Koehler (1929) defines raised grains as the corrugated appearance of a planed surface. This is mainly caused by the effect of the planer knives crushing the hard summerwood into the softer springwood beneath it. In this process, the springwood cells underneath gradually try to regain their original shape to some extent causing the summerwood to rise up. In the present case, edge sharpness could not have caused the defects related with grains as freshly ground blades were used in the study. The not too high density may be one reason. However, Bustos et al. (2010) clearly found that the cutting edge-recession increased with increasing use of planer blades.

Table 5 reveals that most of the samples lie in the grade 1 (defect-free) category when planed with different cutting angles. It can also be seen that the $25^{\circ}$ gives the highest defect free surfaces $(60 \%)$ closely followed by $30^{\circ}$ which gives $57 \%$ defect-free surfaces. This means that for this species, it is better to keep the cutting angle on the higher side. Hence, a cutting angle of $25^{\circ}-30^{\circ}$ is recommended for M. dubia species. For further calculations, the value of $60 \%$ was adopted. The Corresponding grade factor for Tectona grandis in planing with a cutting angle of $25^{\circ}$ is $20 \%$ (Pant et al. 2003). Thus, as far as planing is concerned, M. dubia performs much better than Teak. It is worth mentioning that Azadirachta indica, Albizzia and Chukrasia tabularis (belonging to Meliaceae family) were reported to be planed to smooth surfaces with planer cutters having $25^{\circ}$ cutting angles whereas species like Acacia nilotica, A. catechu, Cedrus deodara etc. required a cutting angle of $30^{\circ}$ (Shukla et al. 1991).

The percent grade values obtained for the other operations are given in Table 6. The values reported for $T$. grandis by Pant et al. (2002) also are included in the Table 6 . 
Table 6: Percentage of different Grades of M. dubia along with those for T. grandis.

\begin{tabular}{|c|c|c|c|}
\hline Operation & Grades & M. dubia & $\begin{array}{c}\text { T. grandis } \\
\text { (Pant et al. 2002) }\end{array}$ \\
\hline & 1 & 33 & 56 \\
\hline \multirow{5}{*}{ Sanding } & 2 & 10 & 44 \\
\hline & 3 & 40 & 0 \\
\hline & 4 & 17 & 0 \\
\hline & 5 & 0 & 0 \\
\hline & 1 & 50 & 10 \\
\hline \multirow{5}{*}{ Shaping } & 2 & 30 & 20 \\
\hline & 3 & 13 & 35 \\
\hline & 4 & 07 & 35 \\
\hline & 5 & 0 & 0 \\
\hline & 1 & 0 & 43 \\
\hline \multirow{5}{*}{ Boring } & 2 & 0 & 30 \\
\hline & 3 & 03 & 23 \\
\hline & 4 & 37 & 04 \\
\hline & 5 & 60 & 0 \\
\hline & 1 & 0 & 34 \\
\hline \multirow{5}{*}{ Mortising } & 2 & 10 & 50 \\
\hline & 3 & 07 & 16 \\
\hline & 4 & 37 & 0 \\
\hline & 5 & 46 & 0 \\
\hline & 1 & 13 & 36 \\
\hline \multirow{4}{*}{ Turning } & 2 & 0 & 26 \\
\hline & 3 & 0 & 22 \\
\hline & 4 & 0 & 14 \\
\hline & 5 & 87 & 02 \\
\hline
\end{tabular}

From grading data reported in Table 5 and Table 6, Rating factors for each operation were calculated for the species under study and are presented in Table 7 along with those reported for T. grandis (Pant et al. 2002).

Table 7: Rating factors of and M. dubia evaluated from percentage of defects along with those of T. grandis.

\begin{tabular}{|l|c|c|c|c|c|c|}
\hline \multicolumn{1}{|c|}{ Species } & Planing & Sanding & Shaping & Boring & Mortising & Turning \\
\hline $\begin{array}{l}\text { Tectona grandis } \\
\text { (Pant } \text { et al. 2002) }\end{array}$ & 20 & 56 & 33 & 73 & 100 & 84 \\
\hline Melia dubia & 60 & 33 & 80 & 00 & 17 & 13 \\
\hline
\end{tabular}

Rating factors indicate the extent to which a wood worker can tolerate defects in finishing operation. It can be seen from Table 7 that $M$. dubia shows a much better performance than teak as far as planing and shaping operations are concerned. However, it would be interesting to mention that the wear of the planing blade increases with increasing length of planing (Bustos et al. 2010). They used planer blades which had undergone wear due to planing four levels of lengths ranging from 200 to $30000 \mathrm{~m}$. The tensile shear strength of lap joints made with radiata pine was reported to decrease significantly with planing length and the resulting knife wear. Careful sanding has been reported to remove defects caused during planing in the case of Eucalyptus hybrid 
(Jaitly et al. 1983).

In shaping, the most common defects found were raised and torn grains. The defect that was most prevalent in five species of Eucalyptus was torn grain in shaping trials (Belleville et al. 2016). During moulding of plantation-grown Picea glauca also torn grain was reported as the main defect (Hernández et al. 2001).

Scratching (caused by uneven grits) and snake (spiral) marks were not observed in any specimen after sanding. However, fuzziness or woolly surface and torn grain were noticed on the specimen. Sanding is already reported to cause more fuzziness than planing since the grits on the sand papers tear up parts of fibers, whereas the planer blade usually cuts through the fibres resulting in lesser numbers of loose ends sticking up (USDA 1955). The surface finish produced for eucalyptus spp. was very smooth when Belleville et al. (2016) used higher grit sized sand papers. Hazir et al. (2017) cites the report of Varanda et al. (2010) which reveals that smaller abrasive grains resulted in higher surface roughness of the samples of Eucalyptus grandis. Roughness parameters of samples sanded with 180 grit were lower in contrast to samples planned or sanded with 60 grit (Relaño et al. 2017). The occurrence of torn grains in $M$. dubia during sanding may thus be mostly attributed to the tearing of fibres and use of relatively smaller grits used in the test.

The most common defects that were observed during turning were raised grain, torn and chipped grain with charring effects. With a rating factor of just 13 (against 84 for teak) M. dubia does not look to be good for turning purpose and therefore cannot be recommended for the small scale or handicraft units making round toys.

Raised, torn, chipped and fuzzy grains were the common defects observed during boring. A close-up view of the bored holes is shown in figure 2. Belleville et al. (2016) observed that the denser species of eucalyptus showed better boring performances than lighter timbers. Hernández et al. (2001) also reported good boring, planing and shaping performances for higher density Picea glauca which were obtained from different provenances. Their sample size for boring was done on the shaped samples which were $305 \mathrm{~mm}$ long. A rating factor of zero (Table 7) indicates that $M$. dubia is not at all suitable for the boring operation. This can be attributed to the relatively low density of this species as reported by Kumar et al. (2018).

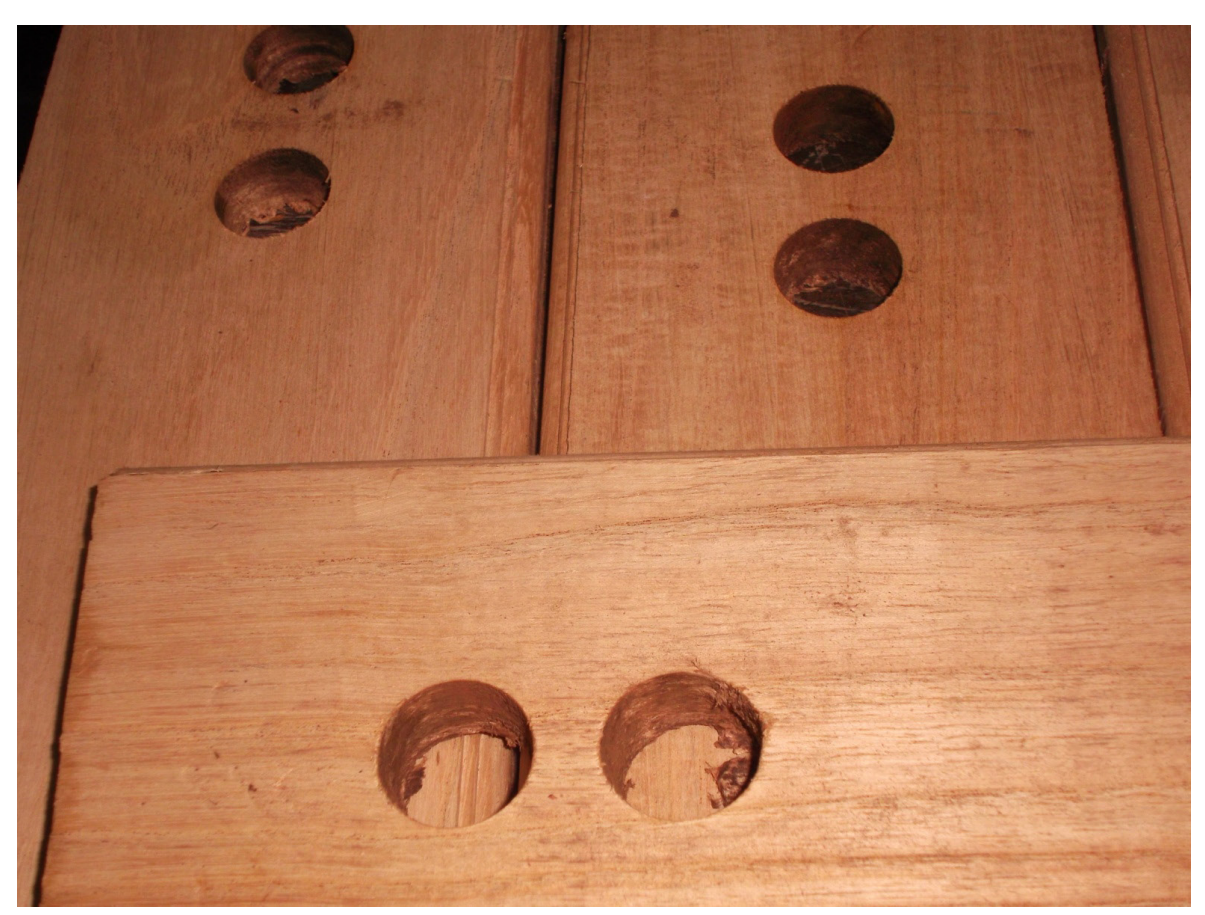

Figure 2: Close up view of bored holes.

The common defects that were noticed during mortising were raised, torn, chipped and fuzzy grains. 
Sometimes the wood is completely chipped out. This is a very serious defect as such defects make the product weak from the point of view of a joint. Occurrence of torn grain is usually caused by dull cutting edges and/ or irregular grain direction that tend to extend into the wood (USDA 1955). On the whole, M. dubia does not seem to be a good species for the making mortise joints.

The next step is to calculate the weighted averages as described in the methodology. For calculation of this, the adjustment factors for $T$. grandis and weights assigned to each operation needs to be taken into account. Adjustment factors are calculated from Table 7 by dividing the rating factor of planing by the rating factors of each operation for teak. For instance, the rating factor for turning is 84 and that for planing is 20 . Hence the adjustment factor of turning would be $20 / 84$. Table 8 gives the adjustment factors and weightages assigned to each operation (Pant et al. 2003).

Table 8: Teak adjustment factors and weightages of different operations.

\begin{tabular}{|l|c|c|c|c|c|c|}
\hline & Planing & Sanding & Shaping & Boring & Mortising & Turning \\
\hline Adjustment factor (Ai) & 1 & 0,357 & 0,606 & 0,274 & 0,2 & 0,238 \\
\hline Weights (Wi) & 4 & 5 & 2 & 1 & 1 & 2 \\
\hline
\end{tabular}

(Pant et al. 2003)

Weightages $\left(\mathrm{W}_{\mathrm{i}}\right)$ are given to each operation as per its importance in working with wood. For example, the weightage for sanding is the highest (5) because sanding is required in almost every type of wood products as described earlier. The total $\left(\sum \mathrm{Wi}\right)$ weight is 15 .

The weighted averages were then calculated using Equation 1 with the values in Table 7 and Table 8 which came out to 22,40 for T. grandis and 23,74 for M. dubia. Using Equation 2, the composite rating factor for $M$. dubia was calculated to be $135,15 \%$. With a composite rating factor of more than $100 \%$ one can say that the overall performance of $M$. dubia is better than that of teak as far as wood working operations are concerned. This is based only on the results of the defects that were observed on this species. As seen earlier, this result is mainly due to the high performance in planing and shaping and reasonable performance in sanding.

However, the actual working quality involves the calculation of Working Quality Index (WQI) which takes into account the power requirements in addition to the defect pattern. The power requirements are reflected through the ease factor described in the materials and methods section.

Ease factor is an indication of ease of working of the species under study relative to teak in wood working tests. It is quantitatively evaluated by measuring power requirements per $\mathrm{cm}$ width of the species studied under planing operation.

It was observed that during planing operation:

- Power requirement in cutting condition measured $=1,25 \mathrm{~kW} / \mathrm{cm}$

- $\quad$ Power requirement in idle running condition measured $=0,96 \mathrm{~kW} / \mathrm{cm}$

- Thus, the Power requirement of $M$. dubia $=1,25-0,96=0,29 \mathrm{~kW} / \mathrm{cm}$

- The power requirement reported for planing of T. grandis is 0,27 kW/cm (Pant et al. 2002).

Hence, the ease factor for M. dubia was calculated using Equation 4 as Equation 6:

$$
E F=\frac{0,27}{0,29} \times 100=93,1 \%
$$

This indicates that M. dubia is not as easy to be worked upon compared to teak. However, we saw that the overall response (CRF) to the working operations were better for M. dubia. The actual WQI would include 
contributions both from CRF and EF of M. dubia.

The working quality index (WQI) was calculated by combining the composite rating factor and ease factor using Equation 5 as 107,12. Thus, though in three operations M. dubia has not performed well compared to $T$. grandis, due to the very high performance in planing, the species has shown a slightly better WQI.

Figure 3 represents the comparative performance of M. dubia with T. grandis taken as 100 under easiness of working (EF), overall wood working performance (CRF) and actual calculated Working quality index (WQI) as discussed above.

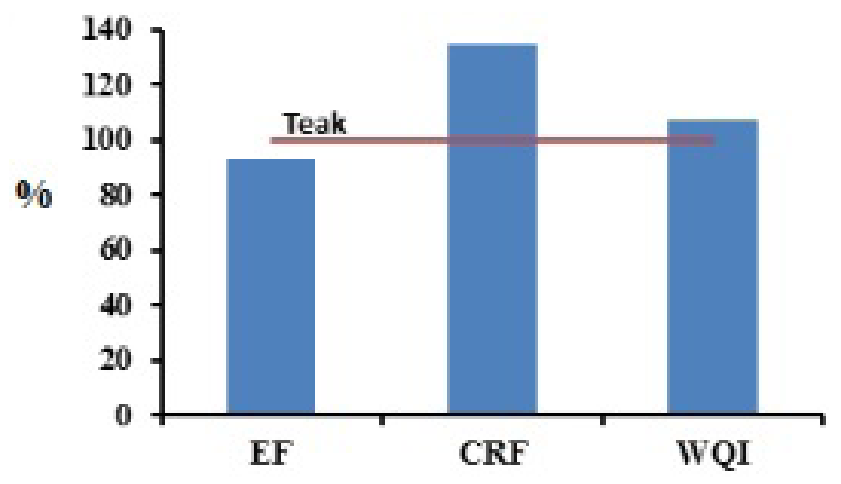

Figure 3: Comparative values of ease of working, overall working performance and working quality index of M. dubia taking T. grandis as 100 .

It is a fact that if a species shows good behavior in one machining quality, then it need not automatically give good results in other machining operations also. This fact can be very much seen with $M$. dubia where the species shows very good performances as far as planing and shaping are concerned but seems to be a poor performer in three other basic operations. This fact in turn benefits the end user in rejecting this species in certain specific uses like turnery products. The composite rating factor and WQI (Working Quality Index) thus present the gross behavior of species in wood machining operations, a property useful in promoting a species for broader end use and substitution of traditional woods by alternate species.

\section{CONCLUSIONS}

The study indicates that ease of working of Melia dubia is comparable to teak which means that the power requirement is nearly same for the species as that of teak. The overall performance (Composite Rating Factor) is higher than that of teak which indicates its overall behavior under the six different machining operations. Although the overall performance of $M$. dubia is better than teak, when operations are looked at individually, the species shows its best results under planing and shaping operations. The surface of this species showed reasonably good performance in sanding also. Though the other three operations are not good performers, the working quality of Melia dubia is just above as that of teak.

\section{REFERENCES}

ASTM International. ASTM. 1987. Standard methods for conducting machining tests of wood and wood base materials ASTM D-1666. 1987. P. 237 - 256.

Belleville, B.; Ashley, P.; Ozarska, B. 2016. Wood machining properties of Australian plantation-grown 
Eucalypts. Maderas-Cienc Tecnol 18 (4): 677-688.

Bureau of Indian Standards. BIS IS. 1992. Evaluation of working quality of timber under different wood working operations- Method of test BIS IS-8292. 1992. New Delhi, 7p.

Bustos, A.C.; Moya L.C.; Lisperguer, M.J.; Viveros, M.E. 2010. Effect of knife wear on the gluability of planed surfaces of radiata pine. Wood and Fiber Science 42(2): 185-191.

Gupta, S.; Singh, C.P.; Kishan-Kumar, V.S. 2016a. Gloss of four common wood coatings measured before and after their exposure to high humidity. Ciência da Madeira (Brazilian Journal of Wood Science) 7(2): 94-99.

Gupta, S.; Shukla, S.; Kishan-Kumar, V.S. 2016b. Efficiency of some common coatings in controlling water vapour absorption by wood substrate. Indian Forester 142(8): 774-780.

Hazir, E.; Hüseyin-Koc, K.; Hiziroglu, S. 2017. Optimization of sanding parameters using response surface methodology. Maderas-Cienc Tecnol 19(4): 407-416.

Hernández, R.E.; Bustos, C.; Fortin, Y.; Beaulieu, J. 2001. Wood machining properties of white spruce from plantation forests. Forest Products Journal 51(6): 82-88.

Jaitly, V.P.; Pant, B.C.; Gupta, S.B. 1983. A note on working and finishing qualities of Eucalyptus species. Indian Forester 109(12): 917-925.

Koehler, A. 1929. Raised Grain-Its Causes and Prevention. Southern Lumberman 137: 210-210.

Kumar, S.; Kelkar, B.U.; Mishra, A.K.; Jena, S.K. 2018. Variability in physical properties of plantation-grown progenies of Melia composita and determination of a kiln-drying schedule. Journal of Forestry Research 29(5): 1435-1442.

Pant, B.C.; Singh, S.P.; Gupta, S.; Sharma, C.M. 2002. Working qualities of some Indian timbers - Part X. Indian Forester 128(09): 1021-1032.

Pant, B.C.; Shukla, K.S.; Badoni, S.P. 1989. Working qualities of Indian timbers - Part VIII. Indian Forester 115(09): 644-660.

Pant, B.C.; Shukla, K.S.; Badoni, S.P. 1992. Working qualities of Indian timbers - Part IX. Indian Forester 118(08): 573-582.

Pant, B.C.; Gupta, S.; Singh, S.P.; Badoni, S.P. 2003. Working and Finishing qualities of some Andaman timbers. Indian Forester 129(04): 479-488.

Relaño, R.L., Lobera, A.S.; Villasante, A.; Espí, P.L.P.; Rojas, J.A.M.; Hermosilla, J.A.; Montero, R.S.; Peña, S.V. 2017. Effect of the anatomical structure, wood properties and machining conditions on surface roughness of wood. Maderas-Cienc Tecnol 19(2): 203-212.

Saravanan, V.; Parthiban, K.T.; Thiruneraiselvan, S.; Kumar, P.; Vennila, S.; Umesh-Kanna, S. 2014. Comparative study of wood physical and mechanical properties of Melia dubia with Tectona grandis at different Age Gradation. Research Journal of Recent Sciences 3(ISC-2013): 256-263.

Saravanan, V.; Parthiban, K.T.; Sekar, I.; Kumar, P.; Vennila, S. 2013a. Radial variations in anatomical properties of Melia dubia cav. at five different ages. Scientific Research and Essays 8 (45): 2208-2217.

Saravanan, V.; Parthiban, K.T.; Kumar, P.; Marimuthu, P. 2013b. Wood Characterization studies on Melia dubia cav. for Pulp and Paper Industry at different Age Gradation. Research Journal of Recent Sciences 2 (ISC-2012): 183-188.

Shukla, K.S.; Badoni, S.P.; Pant, B.C. 1991. Working and carving qualities of Indian timbers. Wood (Oct - Dec): 29 - 34.

Uday, D.N.; Sujatha, D.; Pandey, C.N. 2012. Suitability of Melia dubia (malabar neem wood) for plywood manufacture. Journal of the Indian Academy of Wood Science 8(2): 207-211. 
USDA. 1955. Raised, loosened, torn, chipped, and fuzzy grain in lumber. Report No. 2044, Forest Products Laboratory, Madison, Wisconsin, 22p.

Varanda, L.D.; Alves, M.C.S.; Gonçalves, M.T.T.; Santiago, L.F.F. 2010. Influência das variáveis no lixamento tubular na qualidade das peças de Eucalyptus grandis. Cerne 16:23-32. 